Samara and Leucht are dismissive of Chinese data, even though their original protocol stated they would be included in their meta-analysis. Furthermore, there are increasing calls to include such data. ${ }^{4}$ In a review of PubMed English-language articles published in 2000 and 2010, 11\% of retractions were from China, while 33\% were from the USA. Both Chinese studies in our meta-analysis were identified in the Cochrane database and analysed for risk of bias.

1 Samara MT, Dold M, Gianatsi M, Nikolakopoulou A, Helfer B, Salanti G, et al. Efficacy, acceptability, and tolerability of antipsychotics in treatmentresistant schizophrenia: a network meta-analysis. JAMA Psychiatry 2016; 73 : 199-210.
2 Siskind D, McCartney L, Goldschlager R, Kisely S. Clozapine v. first- and second-generation antipsychotics in treatment-refractory schizophrenia: systematic review and meta-analysis. Br J Psychiatry 2016; 209: 385-92.

3 Li T, Puhan MA, Vedula SS, Singh S, Dickersin K. Network meta-analysis: highly attractive but more methodological research is needed. BMC Med 2011; 9: 79 .

4 Cohen JF, Korevaar DA, Wang J, Spijker R, Bossuyt PM. Should we search Chinese biomedical databases when performing systematic reviews? Syst Rev 2015; 4: 1

Dan Siskind, Metro South Addiction and Mental Health Services, Brisbane, and Melbourne Health, Melbourne, Victoria, Australia. Email: d.siskind@uq.edu.au; Lara Mccartney, Melbourne Health, Melbourne, Victoria, Australia; Steve Kisely, Metro South Addiction and Mental Health Services, Brisbane, and University of Queensland school of Medicine, Brisbane, Australia

doi: 10.1192/bjp.210.4.299a poems

by

doctors

\title{
And They Call It A Fucking Science!
}

\author{
Jo McFarlane
}

Believe it or not, but if you read the DSM

(Diagnostic \& Statistical Manual),

BPD is probably the least insulting

personality disorder to be labelled with.

When it dawned on me that

'having a histrionic flavour to her presentation'

didn't describe the packet of crisps I was holding,

but my dress sense!

Well, I was understandably indignant.

Now it just amuses me

to trawl the list of character traits

that define me to be an aberration.

Apparently being 'spirited', 'animated' and 'charming'

are signs of this - or, to put it another way,

'the seductiveness of the histrionic

mixed with the energy typical of a hypo-mania

Who actually believes this diagnosis

to be anything more than judgemental hocus pocus?

Dr, if you don't like me - just come out and say it.

Truth is: you're not my cup of tea either.

Selected by Femi Oyebode. From Stigma \& Stones: Living with a Diagnosis of BPD, poems by Sally Fox \& Jo McFarlane.

(c) Jo McFarlane. Reprinted with permission.

Through their collection Stigma \& Stones, writers/performers/partners Sally Fox and Jo McFarlane seek to promote understanding, improve treatment and reduce the stigma of living with a diagnosis of BPD. 